\title{
Cryptic Species: A Mismatch between Genetics and Morphology in Millepora
}

\author{
Craig Tepper ${ }^{1, *}$, Logan Squie rs ${ }^{2}$, Chuck Hay ${ }^{1}$, Danielle Gorbach ${ }^{1}$, Dana Friend ${ }^{3}$, Bob Black ${ }^{1}$, \\ Ben Greenstein ${ }^{3}$, Kevin Strychar ${ }^{2}$
}

\author{
${ }^{1}$ Department of Biology, Cornell College, Mt. Vernon, IA 52314, USA \\ ${ }^{2}$ Life Sciences Department, Texas A\&M-Corpus Christi, Corpus Christi, TX 78412, USA \\ ${ }^{3}$ Department of Geology, Cornell College, Mt. Vernon, IA 52314, USA
}

\begin{abstract}
Millepore morphology is highly variable and shows signs of phenotypic plasticity. Two species of Millepora are present around the is lands of the Bahamas: one exhibiting a strong, blade-like structure, Millepora complanata, and the other having a delicate branch-like structure, Millepora alcicornis. The phylogenetic relationship of these corals has been under considerable debate for many years. The existence of a range of intermediate growth forms exh ibiting characteristics of both recognized species has led to the re-examination of this species complex. Several methods were employed to examine the taxonomic relationship including ecological abundance surveys, morphological thin-section analysis, and sequencing of rDNA internal transcribed spacer (ITS) reg ions. Abundance surveys showed a demarcation of growth forms by depth at two sites but an intermingling of growth forms at a third site. Morphometric analysis resulted in discrimination between $M$. alcicomis, M. complanata and the intermediate growth forms. However, rDNA sequence differences revealed the presence of two distinct clades, each containing members of the two currently recognized species as well as intermediate growth forms. The sequence analysis suggests the presence of two, phenotypically plastic cryptic species. Although limited in scope, our results indicate that caution should be exercised when describing species based on morphology alone and that multiple characters, including genetic information, should be used when describing species relationships.
\end{abstract}

Keywords Millepora, Phenotypic Plasticity, Morpho metric, Cryptic Species, rDNA, ITS

\section{Introduction}

The genus Millepora (family Milleporidae, class Hydrozo a, phylum Cnidaria), commonly referred to as "fire-coral," is an integral part of reef communities[1]. Fire corals serve as important framework builders, second only to scleractinian corals[2]. This framework is supported by an algal zooxanthellate symbiont, which aids in light-enhanced calcification[3]. Millepores are distributed worldwide in tropical seas and typically range in depth from less than $1 \mathrm{~m}$ to approximately $40 \mathrm{~m}[4]$. The habitats they live in can range, depending mostly on growth form, from strong turbulent shallow waters to sheltered deeper waters [5]. The morpholo gy of the millepores is highly variable and is believed to show phenotypic plasticity $[1,6]$.

Phenotypic plasticity is believed to be mo lded by selection, such that certain phenotypes are better able to exploit a given environment[7]. Hence, a given species may exh ibit different phenotypes depending on the environment. Plasticity has

* Corresponding author:

ctepper@corn ellcollege.edu (Craig Tepper)

Published online at http://journal.sapub.org/ms

Copyright (C) 2012 Scientific \& Academic Publishing. All Rights Reserved been described in many marine taxa including corals[8-9], sponges[10], fish[11], barnacles[12], and mollusks [13]. The presence and range of taxa shown to exhibit phenotypic plasticity must be taken into consideration when applying morphological characters to define species.

The various growth forms of Millepora in the Caribbean (Figure 1) range from thinly encrusting sheets and delicate dendroid branches, $M$. alcicornis, to thicker, rigid bladed forms, M. complanata[1]. It is this variation in morphology that has led to constant controversy about Millepore classification. Debate about taxonomy is not restricted to the millepores; morphological plasticity has also been documented in many scleractinian corals[14].

Since Millepora was first recognized by Linnaeus in 1758, many naturalists have worked on the millepores and their research has resulted in numerous and widely varied classification schemes[6]. When first described, millepores were primarily classified using morphological characters such as texture of the surface of the coral, size and shape of pores, stinging properties, and visual appearance[15]. Early investigators[16] found Millepora to be quite diverse and recognized 22 different species from the Caribbean.

Later, Hickson[17] suggested that all recognized species were environmentally controlled growth forms of a single 
Millepora species. Boschma[4] recognized ten species of Millepora, three from the Atlantic Ocean and seven from the Indian and Pacific Oceans. Although 50 species of millepores have been described by Vernon[18], currently there are 17 recognized extant Millepora species; 11 from the Pacific and six from the Atlantic[19-20]. Wide variation in growth form of all species and a lack of diagnostic morphological characters presents serious problems for correct identification at the species level.
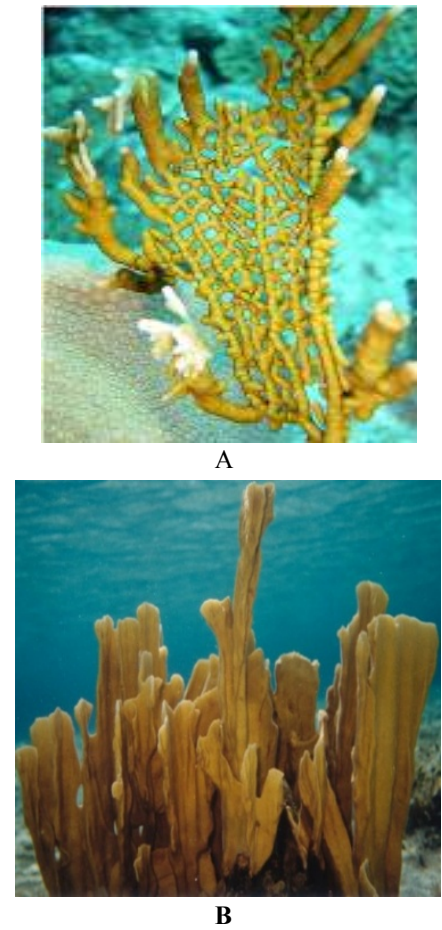

Figure 1. Photographs depicting the typical growth forms of Millepora species found in the Bahamas. A Millepora alcicomis B Millepora complanata

De Weerdt[15] examined the importance of morphologic al characters when distinguishing between species of Millepora. Multiple surveys of $M$. alcicornis and $M$. complanata in the Caribbean showed that the growth forms are widely overlapping in the environments they inhabit. This wide range implied that the differences in morphology could not be attributed solely to plasticity, and that there is a genetic component controlling growth. Transplantation experiments conducted in the Caribbean, showed that bladed forms (M. complanata) developed finger-like projections when relocated to deeper depths, which seems to be optimal for the branching form (M. alcicornis), and that the branching form became more robust when relocated to shallower depths, which seems to be optimal for the bladed form[15]. De Weerdt[15] concluded that morphological characters can change depending on environment and thus are not conclusive indicators of species.

The recent use of rDNA sequence and the development of coral-specific primers have made more accurate taxonomic classification possible. The inherent uncertainty, due to phenotypic plasticity, in using morphological characters as a way to classify species, can be aided by determining genetic distance, or relatedness, between closely related growth forms using rDNA sequences[21]. Previous studies on a wide range of organis ms have suggested that the internal transcribed spacer (ITS) regions of ribosomal DNA (rDNA) are highly variable and thus suitable for comparative genetic studies of closely related species and populations [22-23]. In eukaryotes, the nuclear ribosomal small subunit gene, $18 \mathrm{~S}$, is separated from the $5.8 \mathrm{~S}$ gene by an internal transcribed spacer(ITS-1) region and the $5.8 \mathrm{~S}$ gene is separated fro $m$ the $28 \mathrm{~S}$ gene by ITS-2. Ribosomal genes and their spacers evolve at different evolutionary rates[21] making this gene family an ideal candidate for untangling species taxonomic relationships. The $18 \mathrm{~S}, 5.8 \mathrm{~S}$ and $28 \mathrm{~S}$ genes are highly conserved, but following transcription of these genes, the spacer regions are excised prior to the incorporation of the rRNA into ribosomes. Since the ITS regions do not contribute to formation of the ribosomes, it is somewhat free to accumulate mutations. This leads to higher rates of evolution because the ITS spacers have fewer functional constraints compared to the ribosomal genes (18S, 5.8S and 28S).

Takabayashi et al.[24] examined the ITS regions encompassed by the coral specific primer A18S[25] and the universal primer ITS 4 for seven different coral species. Takabayashi et al.[24] compared the relatedness of samples from Acropora, Seriatopora, Goniopora, Porites, Heliofung ia, and Stylophora to each other, as well as to replicates within the same species. Amplified fragment size and sequence data were used to distinguish between the six different genera mentioned above, and between eight different samples of Acropora longicyathus. Takabayashi et al.[24] reported that the ITS region varied from 2 to $31 \%$ in different coral species making this region ideal for comparative analyses between populations. The ability to distinguish samples between and within species made this fragment a powerful tool for the phylogenetic study of corals.

Meroz-Fine et al.[26] utilized a combination of morphological characters and DNA sequence from the ITS region of the Red Sea fire-coral, $M$. dichotoma, to show that the currently recognized single species with two growth forms (blade and branching) was in fact two distinct species. They reported that the average ITS sequence divergence between growth forms was $11.9 \%$ while the average divergence within a growth form was between 3.7 to $4.5 \%$. Meroz-Fine et al.[26] also reported that they could distinguish between the two growth forms based on the size of the amplified ITS region. The bladed form was composed of 900 base pairs while the branching form was composed of 800 base pairs. While much of the work conducted on Millepora has been done on M. dichotoma, little work has focused on the two prevalent millepores found in the Caribbean.

Initial abundance surveys on Millepora conducted in early 2003 at various sites around San Salvador Island, Bahamas revealed the presence of a wide range of morphologies that did not easily fit into the current classification scheme of the 
two recognized species. The new morphologies showed characteristics of both M. alcicornis and M. complanata (Figure 2). These new growth forms were termed intermedi ates and the present study is an attempt to explain the phylogenetic relationship of these intermed iate growth forms to the other two recognized species.

The purpose of our research is to determine whether the colony morphologies represented by the described species of Millepora are matched by genetic isolation. We hope to distinguish among four hypotheses: 1) Millepores of the Bahamas are heterogeneous assemblages of genetically distinct forms. 2) The described "species" are a spectrum of colony growth forms reflecting ecological conditions rather than genetic isolation. 3) The range of growth forms observed is the result of extensive hybridization. 4) Millepores are reproductively isolated cryptic species and that traditional macro- and microskeletal features used for classification cannot distinguish them.

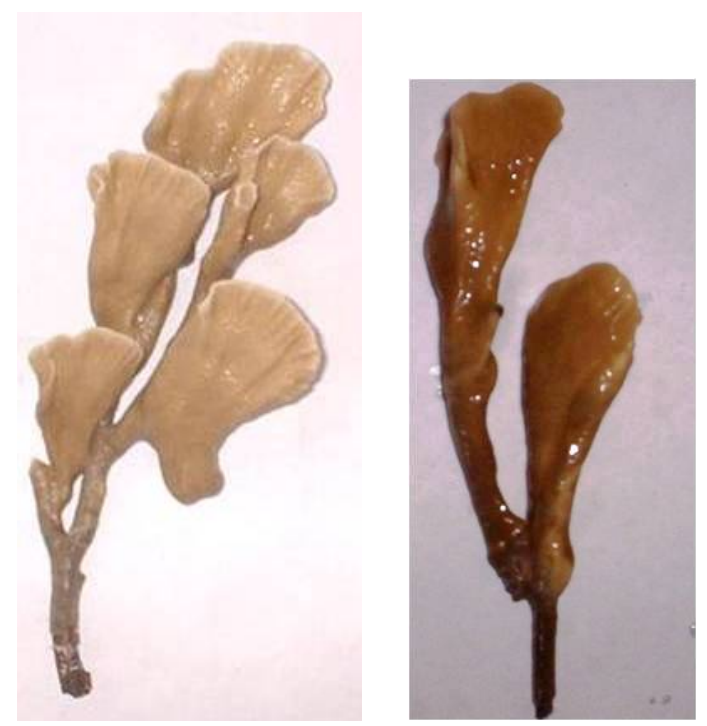

Figure 2. Photographs depicting examples of intermediate growth forms of Millepora found around San Salvador Island, Bahamas

\section{Materials and Methods}

\subsection{Collection Sites}

Millepores used in this study were collected from reefs surrounding the is land of San Salvador, Bahamas (Figure 3). San Salvador is located on the eastern edge of the Bahamas Is land chain and is characterized by its karst and hypersaline lakes. Patch reefs included for collection were Lindsay Reef (2400'32'N, 74³1'59'W), Rocky Point Reef(2406'25'N, $\left.74^{\circ} 31^{\prime} 17^{\prime \prime} \mathrm{W}\right)$, and French Bay (2356'59'N, 74³2'50”W) (Figure 3). Lindsay Reef and Rocky Point Reef are shallow reefs with maximum depths of approximately $5 \mathrm{~m}$. French Bay has both shallow (1-5m) and deep (5-10m) patch reefs.

\subsection{Ecological Abundance Surveys}

Twenty meter line transects were laid down at random points at both French Bay and Lindsay Reef. Transects 1-3m in depth were surveyed by snorkeling, and transects deeper than $3 \mathrm{~m}$ were conducted using SCUBA. All Millepora colonies within one meter of either side of an outstretched tape measure were recorded giving a total area surveyed for each transect of $40 \mathrm{~m}^{2}$. On ly colonies with the classic finely branched morphology were considered to be M. alcicornis and only bladed colonies with a complete absence of branches were considered to be M. complanata. Millepora colonies not meeting these specifications were recorded as intermediate growth forms.

\subsection{Sample Collections}

Coral samples were randomly collected from each of the aforementioned reefs by removing a s mall piece, approxi-. mately 4 sq. cm in size. Samples of M. alcicornis, $M$. complanata, and the intermediate morphology were transported from the collection sites to the Gerace Research Centre (San Salvador, Bahamas) in buckets containing seawater and held in a flow-through seawater tank for no more than two days until coral DNA was isolated.

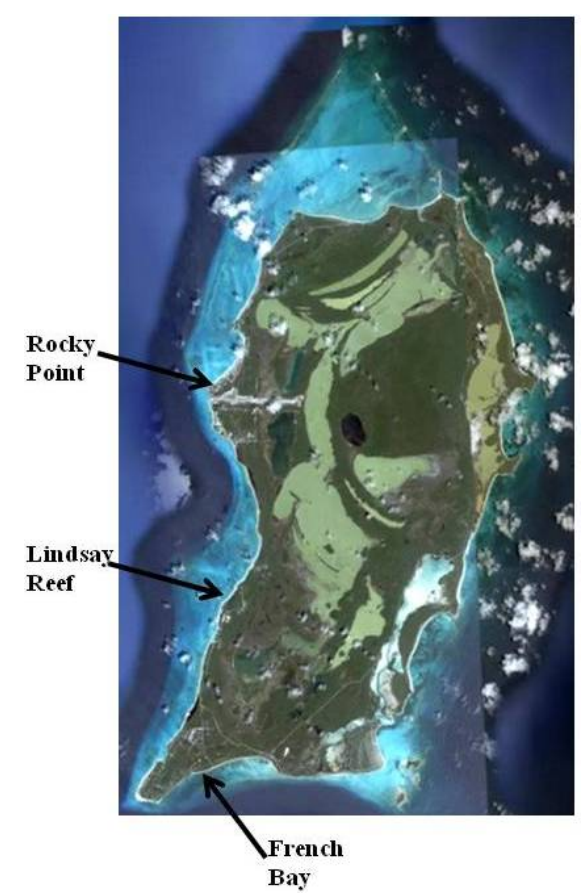

Figure 3. Satellite image San Salvador, Bahamas showing the three collection sites[27]

\subsection{Mor phometric Analysis}

Twelve specimens of Millepora were subjected to morphometric analysis following the method outlined by Amaral et al.[28]. Specimens included five individuals assigned to $M$. complanata, three individuals of $M$. alcicornis and four individuals that exhibited intermediate growth forms.

Specimens were cut and mounted onto standard microsco pe slides, ground to standard thin sections $(30 \mu)$ and analyz ed using a petrographic microscope. A series of $25 \mathrm{~mm}^{2}$ grids was superimposed on each thin section such that replicate, non-overlapping grids could be analyzed. Each 
grid was photographed using a SONY ExwaveHAD digital video camera and imported into Photoshop for analysis.

A variety of features of the skeletal microstructure were quantified using the Analysis Tools module in Photoshop. These included diameter and surface area of all gastropores and dactylopores, distance between gastropores, dactylopor es, and their density (\# pores/grid). The number of dactylopores associated with each gastropore also was recorded. Variable numbers of individual gastropores (8-23) and dactylopores (27-129) were measured from each grid. Total number of grids measured was determined by the surface area of the hydrozoan present on each thin section. $\mathrm{N}$ $=3-5$ grids per coral (8-129/grid, see above). Within-and between-grid values were averaged. Since no difference was observed using pooled vs. unpooled data, pooled data from each specimen are presented here. A Q-mode distance matrix was generated from the average values obtained from each specimen using the Euclidean Distance Coefficient. The matrix was subjected to Cluster Analysis (UPGMAA algorithm). An Analysis of Similarity (ANOSIM)[29] was performed to assess significance of the differences observed between samples (both procedures in Primer v. 6.15). The Q-mode dendrogram was compared to the results of molecular genetic analysis.

\subsection{DNA Tec hni ques}

Genomic DNA was isolated using a procedure modified from Rowan and Powers[30] and Lopez et al.,[31]. Coral tissue was removed by repeatedly blasting the skeleton with a 50cc syringe containing L buffer (100mM EDTA, $10 \mathrm{mM}$ Tris, $\mathrm{pH}$ 7.6). Coral tissue was centrifuged at $3500 \mathrm{rpm}$ for 10 minutes; the resulting pellet was washed in $10 \mathrm{~mL}$ of $\mathrm{L}$ buffer and re-centrifuged. The tissue pellet was resuspended in $900 \mu \mathrm{L}$ of L buffer and macerated manually with a tissue homogenizer. The homogenate was centrifuged twice at $500 \mathrm{rpm}$ for 10 minutes in order to separate the coral tissue from the liberated zooxanthellae. Following the addition of $1 \%(\mathrm{w} / \mathrm{v})$ SDS to the supernatant, the lysate was incubated at $65^{\circ} \mathrm{C}$ for $30-60$ minutes. Pro $\mathrm{K}(0.5 \mathrm{mg} / \mathrm{mL})$ was added and the lysate was incubated at $37^{\circ} \mathrm{C}$ for at least 6 hours. $\mathrm{NaCl}$ $(0.8 \mathrm{M})$ and CTA B $(1 \% \mathrm{w} / \mathrm{v})$ were added and the sample was incubated at $65^{\circ} \mathrm{C}$ for 30 minutes. Nucleic acids were precipitated twice in $70 \%(\mathrm{v} / \mathrm{v})$ ethanol and $3 \mathrm{M}$ sodium acetate ( $\mathrm{pH}$ 5.2) and immediately centrifuged. Following resuspension of the pellet in $\mathrm{dH}_{2} \mathrm{O}$, the DNA was briefly centrifuged and the supernatant was retained.

ITS rDNA PCR amplification was performed using 100-300ng of template, $60 \mathrm{p} \mathrm{mol}$ of the coral specific primer A 18S (5'-GATCGAAC-GGTTTA GT GA GG-3') and $60 \mathrm{p} \mathrm{mol}$ of the universal primer ITS 4 (5'-TCCTCCGCTTA TTGATATGC-3')[25], 10X Tfl PCR buffer (Promega, Madison, WI), $2.0 \mathrm{mM} \mathrm{MgSO} 4,0.1 \mathrm{mM}$ dNTP and $1 \mathrm{U}$ of Tfl polymerase. The PCR profile was: 1 cycle of $94^{\circ} \mathrm{C}$ for 2 minutes; 30 cycles of $94^{\circ} \mathrm{C}$ for 1 minute, $55^{\circ} \mathrm{C}$ for 2 minutes, and $72{ }^{\circ} \mathrm{C}$ for 3 minutes; and 1 cycle of $72{ }^{\circ} \mathrm{C}$ for 5 minutes[26]. Amplified PCR products were run on $1.2 \%$ (w/v) low melting agarose gels. Discreet, prominent bands were excised and purified using the Wizard SV Gel and PCR Clean-Up System (Promega). Purified PCR products were ligated into pGEM-T vectors following the manufacturer's protocol(Promega) and trans formed into co mpetent DH5 $\alpha E$. coli host cells. Following blue-white selection, positive colonies were harvested and plasmid DNA was isolated using the Zyppy Plasmid Miniprep Kit (Zymo Research, Orange, CA). Plas mids containing ITS rDNA inserts were sequenced in both directions with 3.0 pmol of M 13 forward and reverse primers. Reagents and reaction conditions for sequencing were as specified by the USB Thermo Sequenase Cycling Sequencing Kit (USB, Cleveland, OH). PCR products were run in $5.5 \% \mathrm{~KB}^{\mathrm{Plus}}$ Gel Matrix acrylamide using a LI-COR 4300 DNA Analyzer (LI-COR, Lincoln, $\mathrm{NE}$ ). Sequence reaction products were analy zed using e-Seq V3.0 (LI-COR).

\subsection{Phylogenetic Analysis}

Maximum likelihood trees were produced using MEGA 4.0.1. The sequence of Millepora exaesa[32] was used for the outgroup (GenBank, accession no. U65484) and 1000 bootstrap replicates were performed. Nucleotide percent substitution was also calculated from sequence data and compared within and between morphologies using MEGA 4[33] (The Biodesign Institute, Tempe, AZ).

\section{Results}

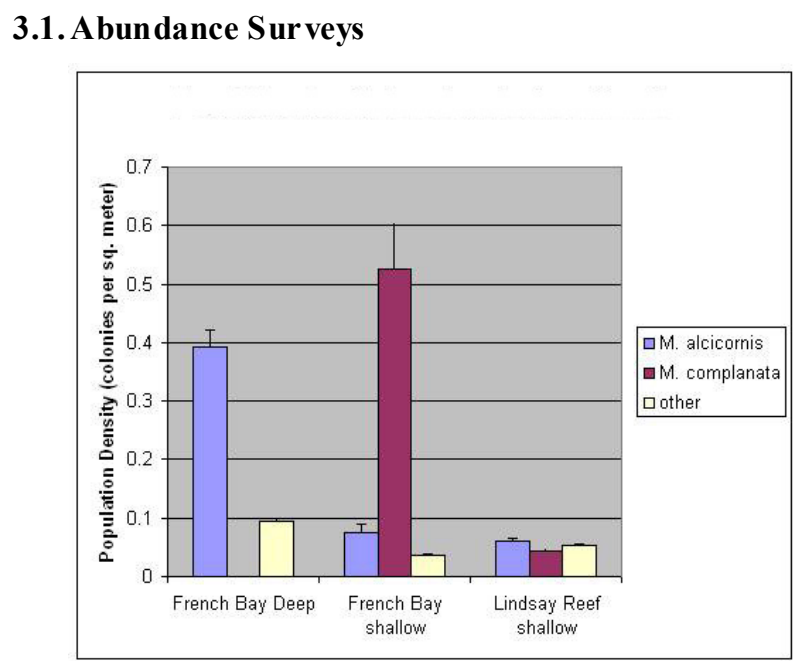

Figure 4. Population density of millepores separated by depth and specific reef. Error bars represent standard error of the mean. Shallow $=1-3 \mathrm{~m}$ and deep $>3 \mathrm{~m}$. Data shown are from French Bay and Lindsay Reef. N (number of transects) $=19$ for French Bay deep (total of 370 colonies were counted; 299 alcicomis, 0 complanata and 71 intermediates), $\mathrm{N}=24$ for French Bay shallow, (total of 557 colonies were counted; 66 alcicomis, 463 complanata and 28 intermediates) and $\mathrm{N}=10$ for Lindsay Reef (totalof 63 colonies were counted; 24 alcicomis, 17 complanata and 22 intermediates)

Yearly reef surveys were conducted between 2003 and 2009. Year to year variability was minimal and the same trends were exhibited on individual reefs. Representative 
data are shown in Figure 4 for French Bay and Lindsay Reef. The two locations surveyed exhibited different assemblages of Millepora. Lindsay Reef is a shallow reef that contained similar, low densities of M. alcicornis, M. complanata and intermediate growth forms. In contrast, shallow reefs in French Bay included both species and intermediates, but $M$. complanata colonies were far more abundant than either $M$. alcicornis or the intermediate growth forms. Deep reefs in French Bay contained only $M$. alcicornis and the intermediate growth forms; no M. complanata colonies were observed in these transects.

\subsection{Mor phome tric Analysis}

Morphometric data were able to discriminate between the two standard Milleporid taxa (M. complanata and $M$. alcicornis) as well as those specimens exhibiting an intermediate growth form (Figure 5). Specimens of $M$. alcicornis are "tacked on" to the cluster containing the intermediate growth forms at relatively low similarity values.

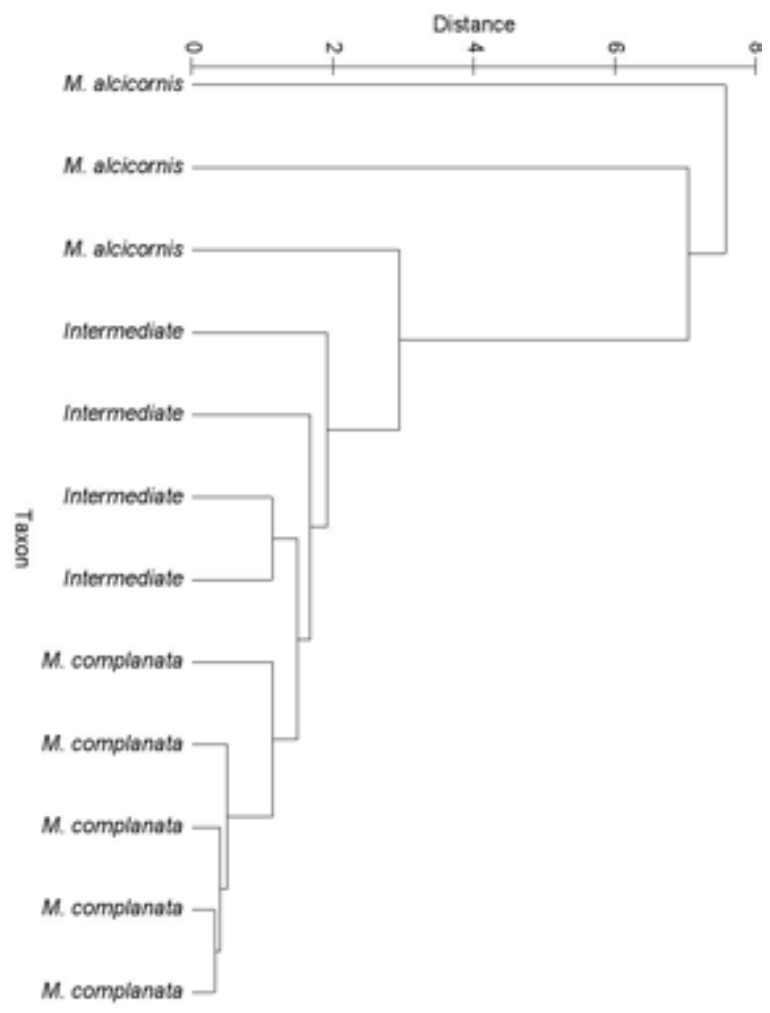

Figure 5. Dendrogram obtained from reduction of a Q-mode Euclidean Distance Matrix. Differences between specimens are significantly different ( $\mathrm{p}<0.05$ ) across the three growth forms (M. complanata, M. alcicomis and Int ermediate)

\subsection{PCR Amplification of rDNA}

Frag ments of the ITS rDNA region (18S rDNA, ITS-1, 5.8S rDNA, ITS-2, and 28S rDNA) were amplified from bladed, branching and intermediate growth forms and a single PCR amplification product of approximately 825 base pairs was obtained fro mevery samp le (Figure 6).

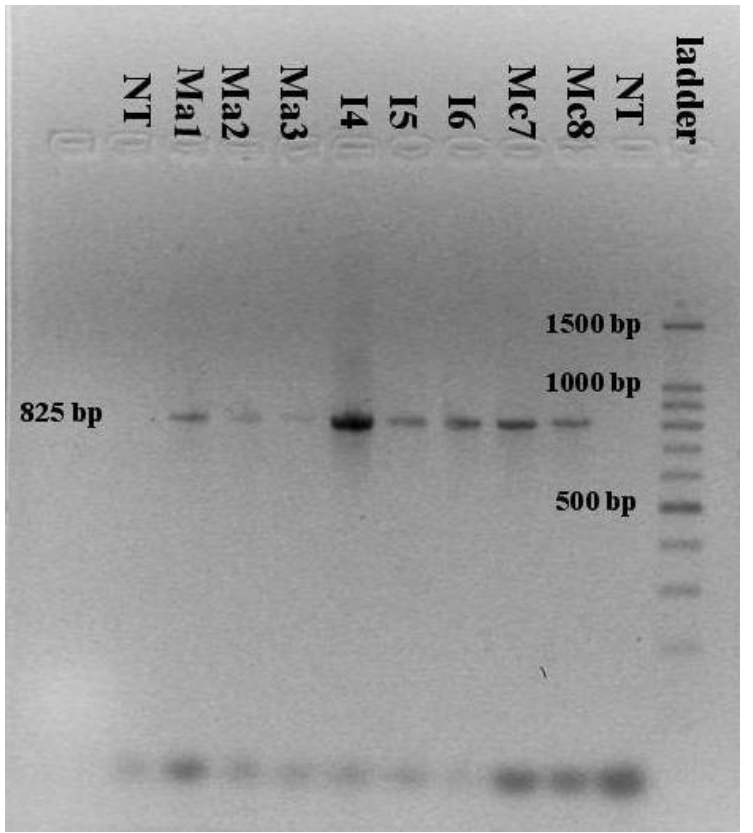

Figure 6. PCR amplification of rDNA using the A1 8S/IT S 4 primers. The single band corresponds to a size of approximately 825 base pairs. $\mathrm{Ma}=M$. alcicornis (branched growth form), $\mathrm{I}=$ intermediate and $\mathrm{Mc}=M$. complanata (bladed growth form). The number following the sample name denotes the sample number. $\mathrm{NT}=$ no template controls and a 100 base pair ladder is shown

\subsection{DNA Sequence Analysis}

A total of 36 samples were sequenced (17 of $M$. complanata, 12 of $M$. alcicornis, 7 intermediate growth forms) each yielding a sequence length of appro ximately 825 base pairs. The aligned sequences including gaps were 843 sites long and contained 778 conserved sites, 50 variable sites, and 10 parsimony informative sites.

Genetic variation, as nucleotide percent substitution, both within and between morphologies of $M$. alcicornis, $M$. complanata and intermediate growth forms was relatively low ranging from $0.6 \%$ to $0.9 \%$ (Table 1). Nucleotide substitution rates were higher when $M$. complanata was compared to M. exaesa from the Red Sea[32].

Table 1. Nucleotide Percent Substitution in rDNA Sequence between and with in the Three Morphologies of Millepora using A18S and IT S4 Primers. A Comparison of the rDNA Sequence between $M$. complanata and $M$. exaesa is also Included

\begin{tabular}{|l|c|c|c|}
\hline & M. complanata & M. alcicornis & Intermediate \\
\hline M. complanata & $0.6 \%$ & $0.8 \%$ & $0.6 \%$ \\
\hline M. alcicornis & --- & $0.9 \%$ & $0.6 \%$ \\
\hline Intermediate & --- & --- & $0.7 \%$ \\
\hline M. exaesa & $12.2 \%$ & --- & --- \\
\hline
\end{tabular}

Maximum likelihood (ML) analysis of ITS rDNA sequen ces produced consensus topologies with two major clades (Figure 7). The two clades each contained members of all three morphologies (M. complanata, M. alcicornis, and intermediate growth forms). Bootstrap values for the two main clades of the tree are represented as a percentage and were $75 \%$ for both clades (Figure. 7). 


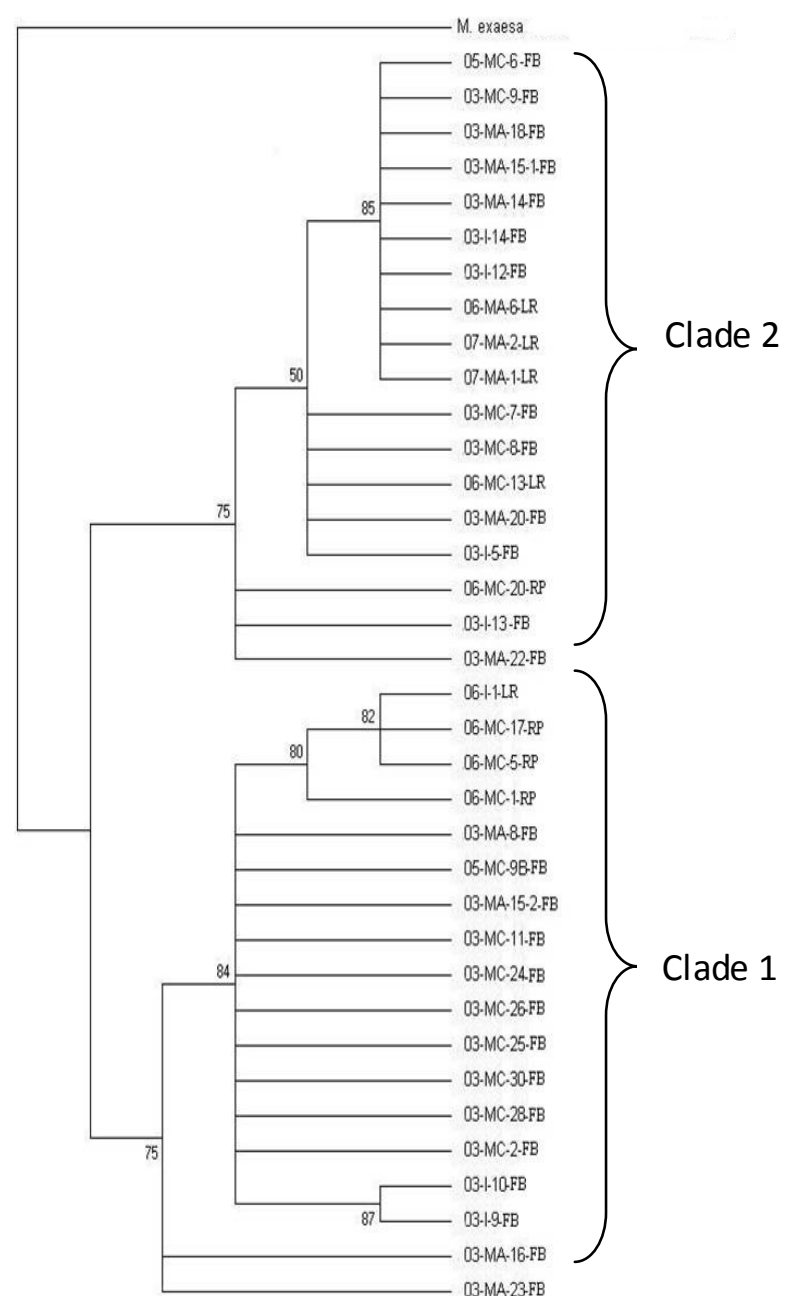

Figure 7. Maximum likelihood tree showing bootstrap values for 36 samples of Millepora from the full range of phenotypes. 03,05 or 06 denote the year the sample was collected $(2003,2005$ or 2006). MA = Millepora alcicornis, $\mathrm{MC}=$ Millepora complanata, $\mathrm{I}=$ intermediate growth form. Numbers after the species designations represent the sample number. FB = French Bay, LR = Lindsay Reef and RP = Rocky Point. Bootstrap values are listed on the branchpoints. M. exaesa was used as the out group

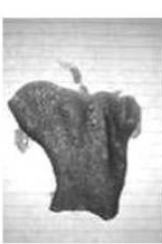

$\mathbf{R P}$

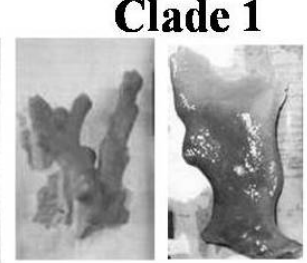

LR

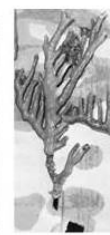

FB

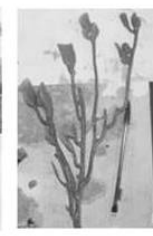

FB
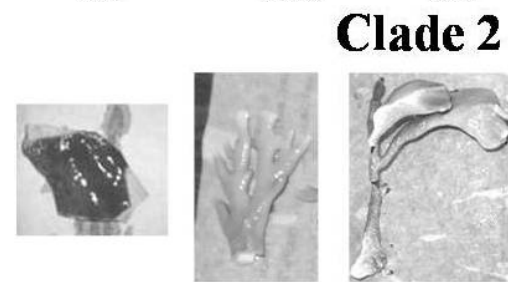

RP

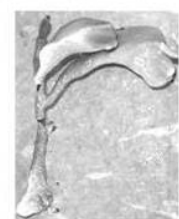

FB

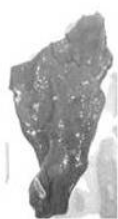

FB

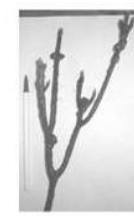

LR

Figure 8. Representatives of Millepora samples that are classified as clade 1 and 2. Collection sites are FB $=$ French Bay reef, $L R=$ Lindsay Reef, and $\mathrm{RP}=$ Rocky Point reef

Table 2. Nucleotide Position within the rDNA Sequence, Nucleotide Polymorphism and Clade Identification of the Conserved Pattern of SNPs Found in all Millepora Samples Sequenced

\begin{tabular}{lccc}
$\begin{array}{l}\text { Nucleotide } \\
\text { Position }\end{array}$ & Clade & $\begin{array}{l}\text { Nucleotide } \\
\text { Polymorphism }\end{array}$ & Region \\
\hline 238 & 1 & C & ITS-1 \\
& 2 & T & \\
284 & 1 & A & ITS-1 \\
& 2 & T & \\
310 & 1 & T & ITS-1 \\
& 2 & A & \\
713 & 1 & T & ITS-2 \\
& 2 & - & \\
733 & 1 & C & ITS-2 \\
& 2 & A &
\end{tabular}

Upon closer examination of the rDNA sequence an interesting pattern emerged. The presence of five single nucleotide polymorphisms (SNPs) were found to be generally conserved across all samples sequenced (Table 2). This set of conserved SNPs directly corresponded with the two different clades formed by the phylogenetic analys is (Figure 7). Members of each morphology, from the full range of phenotypes, were observed in each clade (Figure 8).

\section{Discussion}

The taxonomy of the millepores is currently based on morphological characters and does not take into account genetic differences that may be present[15]. Taken alone, our morphometric results corroborate earlier work that distinguishes between the millepores based on morphology. The fact that $M$. alcicornis was not as clearly differentiated by our cluster analysis may in part be the result of a s maller sample size of this species in thin section (two-dimensional planes obtained fro mbranching hydrozoan colonies are quite small). A more interesting result is the contrast between the outcomes produced by genetic and morphometric data, which suggests that the standard, morphologically based, taxono my may be incorrect; two species of Millepora may exist around San Salvador that cannot be distinguished based upon morphology alone. This hypothes is suggests that two phenotypically plastic cryptic species are present and appear to be reproductively isolated from one another.

Both currently recognized Millepora species are morphologically plastic and their relative abundance was found to be different between study sites. Abundance surveys at French Bay suggest the two morphologies may be utilizing different habitats since one is predominantly found in shallower waters, while the other is found almost exclusively in deeper waters (Figure 4). At first glance, this data seems to support the current taxonomy, but when phenotypic plasticity is incorporated, the various growth 
forms present may simply be the result of the different environments in which they are found. Additionally, the occurrence of all growth forms in mutual proximity on Lindsay Reef supports Stearn and Riding's[1] contention that morphological variation in the Millepores is not primarily a response of a single species to environmental differences. Results from abundance surveys at Lindsay Reef suggest that genetic differences may exist between the growth forms.

Results from thin section analysis support the abundance data but suggests a different taxonomic relationship than the sequence data. Morphometric results indicate that pore size and arrangement can be used as a diagnostic tool to distinguish the two species of Millepora (Figure 5). A possible explanation for this discrepancy with the genetic data is again phenotypic plasticity. While the environment has been shown to alter macro-mo rphological characteristics via plasticity, it is not much of a stretch to suggest that the environment can alter mic ro-morphological characters, such as pore size, as well. While more work needs to be done in this area, it is our assertion that the environment plays a large role in determining the macro and micro morphologies of these corals.

Results from the ITS rDNA sequence comparis on of the two purported species of Millepora and the intermediate growth forms show that the three morphologies are very closely related (Table 1). However, the rDNA ITS region exhibits considerable divergence when compared to the reproductively isolated $M$. exaesa found in the Red Sea.

Takabayashiet al.[24] have shown that the size of the PCR amplified ITS rDNA fragment may be used as a diagnostic marker to distinguish between closely related species. Meroz-Fine et al.[26] reported that two growth forms of $M$. dichotoma that were classified as a single species contained ITS rDNA regions that were quite different in size and sequence leading them to conclude the two growth forms were different species. Regardless of the growth form sequenced, all of our millepore samples had a fragment length of approximately 825 base pairs suggesting that the millepores may be one plastic species. However, the phylogenetic tree (Figure 7) generated fro $m$ these sequences demonstrated the presence of two clades, each containing members of all three morphologies (Figure 8), which further suggests the current taxonomy of Millepora may not be accurate. The conservation of the SNP pattern (Table 2) sugges ts that these two clades are reproductively is olated and the intermediate growth forms are not a result of extensive hybridization.

However, basing species-level phylogenetic reconstructio ns on ITS regions is sometimes problematic due to intragenomic sequence variation in the rDNA tandem repeats[34]. Variant rDNA copies can arise spontaneously in a single generation from point mutations. LaJeunesse and Pinzon[35] maintain that the dominant rDNA sequence in the genome can be used for phylogenetic reconstructions. Sequencing rDNA ITS regions following cloning, as was done in this analysis, sometimes leads to the detection of rare variants in the repeated rDNA sequences[35]. In order to determine whether the SNP pattern we have uncovered is a diagnostic species identifier or is due to the detection of rare cloning variants, we have begun an analysis using PCR-denaturing gradient gel electrophores is in which rare rDNA variants from a single sample can be isolated and sequenced[36].

\section{Conclusions}

Our results indicate the possibility that two reproductively is olated cryptic species that are independent of growth form, depth and reef location may exist off the coast of San Salvador, Bahamas. These results have important implications for using the paleontological record for investigating taxonomic and evolutionary relationships between closely related hydrozoan taxa. Inasmuch as macroand microskeletal features are the only recourse for elucidating such relationships for fossil hydrozoans, we submit that a close examination of the facies in which specimens are preserved accompany their identification. In this fashion, patterns of ecophenotypic plasticity may be explored in tandem with taxonomic analysis.

Many new Caribbean coral species and species complexes have been recognized by integrating molecular genetic and morpho metric analyses [37-38] and these have been extended to include fossil corals[39]. However, the morphometric component of this work is carried out using landmark analyses of scleractinian coral skeletal microstructure. Hydrozoan skeletons are much less complex than those featured by scleractinians (for example no septa, much less septal ornamentation). It is possible that microstructural analyses of hydrozoans simply cannot yield results that mirror molecular genetic analyses.

\section{ACKNOWLEDGEMENTS}

This work was conducted in the Bahamas under a permit granted by the Ministry of Agriculture and Marine Resources. We would like to thank Cornell College undergraduates Pavla Brachova, Peter Lehr, Arno Reichel and Halley Elledge for their assistance with the molecular data and numerous Cornell research classes for the abundance survey data. We would also like to thank Dr. Donald T. Gerace, Chief Executive Officer, and Dr. Tom Rothfus, Executive Director of the Gerace Research Centre, San Salvador, Bahamas. Completion of this work was made possible by Cornell College Faculty Development Grants (BG and CT), a Ringer Endowed Fellowship (CT), McElroy Research Grants (CT), and the LI-COR Biosciences Genomics Education Matching Funds Program (CT).

\section{REFERENCES}


[1] Stearn, C.W., and R. Riding. 1973. Forms of the Hydrozoan Millepora on a recent coral reef. Lethaia 6:187-200.

[2] Stoddart, D.R. 1969. Ecology and morphology of recent coral reefs. Biol Rev $44: 433-498$.

[3] Edmunds, P.J. 1999. The role of colony morphology and substratum inclination in the success of Millepora alcicornis on shallow coral reefs. Coral Reefs. 18:133-140.

[4] Boschma, H. 1948. The species problem in Millepora. Zool Verh Leiden 1:3-115.

[5] Lewis, J.B. 1989. The ecology of Millepora. Coral Reefs 8:99-107.

[6] Lewis, J.B. 2006. Biology and ecology of the hydrocoral Millepora on coral reefs. Advances in Marine Biology 50:1-55.

[7] Gause, G.F. 1947. Problems of evolution. Trans Conn Acad Sci 37:17-68.

[8] Foster, A.B. 1979. Phenotypic plasticity in the reef corals Montastrea annularis (Ellis and Solander) and Siderastrea siderea (Ellis and Solander). J Exp Mar Biol Ecol 39:25-54.

[9] Brown, B.E., L. Sya'rani, and M.D. Le Tissier. 1985. Skeletal form and growth in Acropora aspera (Dana) from the Pulau Seribu, Indonesia. J Exp Mar Biol Ecol 86:139-150.

[10] Palumbi, S.R. 1984. Tactics of acclimation: morphological changes of sponges in an unpredictable environment. Science $225: 1478-1480$

[11] Meyer, A. 1987. Phenotypic plasticity and heterochrony in Cichlasoma managuense (Pisces, Cichlidae) and their implications for speciation in cichlid fishes. Evol 41:1357-1369.

[12] Lively, C.M. 1986. Predator-induced shell dimorphism in the acorn barnacle Chathamalus anisopoma. Evol 40:232-242.

[13] Martín-Mora, E., F.C. James, and A.W. Stoner. 1995. Developmental plasticity in the shell of the queen conch Strombus gigas. Ecol 76:981-994.

[14] Todd, P. 2008. Morphological plasticity in scleractinian corals. Biol Rev 83:315-337.

[15] Weerdt, W.H.de 1981. Transplantation Experiments with Caribbean Millepora Species (Hydrozoa, Coelenterata), Including Some Ecological Observations on Growth Forms. Bijdragen Tot De Dierkunde 51:1-19.

[16] Duchassaing De Fombressin, P., and J. Michelotti. 1864. Supplement Au Memoire Sur Les Coralliares Des Antilles. Mem R Acad Sci Torino 2:97-206.

[17] Hickson, S.J. 1898. Notes on the collection of specimens of the genus Millepora obtained by Mr. Stanley Gardiner at Funafuti and Rotuma. Proc Zool Soc London.

[18] Veron, J.E.N. 2000. In: Staffort-Smith, M. (Eds), "Corals of the World" vols 1-3. Australian Institute of Marine Science, Townsville, Australia.

[19] Weerdt, W.H.de, and P.W. Glynn. 1991. A new and presumably now extinct species of Millepora (Hydrozoa) in the eastern Pacific. Zoologische Mededelingen 65:267-276.

[20] Cairns, S.D., B.W. Hoeksema, and J. van der Land. 1999.
Appendix: List of the extant stony corals. Atoll research Bulletin 459:13-46.

[21] Hillis, D.M., and M.T. Dixon. 1991. Ribosomal DNA: molecular evolution and phylogenetic inference. Q. Rev. Biol. 66:411-453.

[22] Schlotterer, C., M.T. Hauser, A. von Haeseler, and D. Tautz. 1994. Comparative evolutionary analysis of rDNA ITS regions in Drosophila. Molecular Biology and Evolution. 11:513-522.

[23] Chen, C.A., B.L. Willis, and D.J. Miller. 1996. Systematic relationships between tropical corallimporharians (Cnidaria: Anthozoa: Corallimopharia): utility of the $5.8 \mathrm{~S}$ and internal transcribed spacer (ITS) regions of the rRNA transcription unit. B Mar Sci 59(1):196-208.

[24] Takabayashi, M., D. Carter, S. W ard, and O. Hoegh-Guldberg. 1998. Inter- and intra-specific variability in ribosomal DNA sequence in the internal transcribed spacer region of corals. Proc Aust Coral Reef Soc 75th Ann Conf 1:241-248.

[25] Takabayashi, M., D.A. Carter, W.K.W. Loh, and O. Hoegh-Guldberg. 1998b. A coral specific primer for PCR amplification of the internal transcribed spacer region in ribosomal DNA. Mol Ecol 7:925-931.

[26] Meroz-Fine, E., I. Brickner, Y. Loya, and M. Ilan. 2003. The hydrozoan coral Millepora dichotoma: Speciation or phenotypic plasticity? Mar Biol 143:1175-1183.

[27] Online Available: http://earthobservatory.nasa.gov/IOTD/vie w.php?id=76134

[28] Amaral, F. D., M.K. Broadhurst, S.D. Cairns, and E. Schlenz. 2002. Skeletal morphometry of Millepora occurring in Brazil, including a previously undescribed species. Proceedings of the Biological Society of Washington 115 (3): 681-695.

[29] Clarke, K. R., and R.M. Warwick. 1994. Change in marine communities: An approach to statistical analysis and interpretation. National Environment Research Council, UK.

[30] Rowan, R., and D.A. Powers. 1991. Molecular genetic identification of symbiotic dinoflagelletes (Zooxanthellae). Mar Ecol Prog Ser 71:65-73.

[31] Lopez, J.V., R. Kersanach, S.A. Rehner, and N. Knowlton. 1999. Molecular determination of species boundaries in corals: Genetic analysis of the Montastraea annularis complex using amplified fragment length polymorphisms and a microsatellite marker. Biology Bulletin, 196:80-93.

[32] Odorico, D.M., and D.J. Miller. 1997. Internal and external relationships of the Cnidaria: implications of primary and predicted secondary structure of the 5'-end of the 23S-like rDNA. Proc R Soc Lond B Biol Sci 264:77-82.

[33] Kumar S., M. Nei, J. Dudley, and K. Tamura 2008. MEGA: A biologist-centric software for evolutionary analysis of DNA and protein sequences. Briefings in Bioinformatics 9:299-306

[34] Vollmer, S.V. and S.R. Palumbi. 2004. Testing the utility of internally transcribed spacer sequences in coral phy logenetics. Mol. Ecol. 13:2763-2772.

[35] LaJeunesse, T.C. and J.H. Pinzon. 2007. Screening intragenomic rDNA for dominant variants can provide a consistent retrieval of evolutionary persistent ITS (rDNA) 
sequences. Mol. Phy logenet. Evol. $45: 417-422$.

[36] Muyzer, G., E. De Waal, and A.G. Uitterlinden. 1993. Profiling of complex microbial populations by denaturing gradient gel electrophoresis analysis of polymerase chain reaction-amplified genes coding for $16 \mathrm{~S}$ rRNA. Appl. Environ. Microbiol. 59:695-700.

[37] Budd, A. F., T.A. Stemann, and K.G. Johnson. 1994. Sratigraphic distributions of genera and species of neogene to recent Caribbean reef corals. J. Paleont. 68: 951-977.
[38] Knowlton, N., J.C. Lang, and B.D. Keller. 1992. Sibling species in Montastrea annularis, coral bleaching and the coral climate record. Science $255:$ 330-333.

[39] Budd, A. F., and K.G. Johnson. 1996. Recognizing species of Late Cenozoic Scleractinia and their evolutionary patterns, Paleontological Society Papers 1: 59-79. 